\title{
Determining the origin of rate-independent chemoselectivity in CuAAC reactions: An alkyne-specific shift in rate-determining
} step

\author{
Ciaran P. Seath, Glenn A. Burley* and Allan J. B. Watson*
}

Abstract: We report a kinetic and spectroscopic analysis of alkynedependent chemoselectivity in the copper-catalyzed azide-alkyne click (CuAAC) reaction. Studies of six alkyne subtypes reveal that the rate-determining step (RDS) of an aromatic ynamine class is shifted from acetylide formation to the azide ligation/migratory insertion event allowing chemoselectivity independent of overall rate.

The Cu-catalyzed azide-alkyne cycloaddition (CuAAC) or 'click' reaction is an essential transformation used throughout medicinal chemistry, chemical biology, and the material sciences. ${ }^{[1,2]}$ The power and utility of the CuAAC reaction is greatly enhanced by the design of multifunctional molecular scaffolds containing several reactive sites that can be used for sequential chemoselective reactions. ${ }^{[3]}$ The success of this strategy relies on the exploitation of established reactivity profiles of the alkyne and azide partners. ${ }^{[3-6]}$

Current strategies that enable chemoselective control of reactive groups of the CuAAC reaction exploit differences in the reactivity of the alkyne and azide reagents. Specifically, (i) Zhu has shown that chelating groups enable chemoselective control over the azide component. ${ }^{[4]}$ (ii) Carell and Leigh have shown that silyl protecting group strategies provide a robust method for chemoselective control in multi-alkyne systems. ${ }^{[3,5]}$ (iii) Fokin has developed chemoselective CuAAC reactions of 1-iodoalkynes that, due to their mechanistically distinct operation, have allowed for highly chemoselective reactions vs. conventional terminal alkynes. ${ }^{[6]}$

Based on work by Finn and Fokin, ${ }^{[7]}$ and $\mathrm{Zhu},{ }^{[8]}$ acetylide formation is the rate-determining step (RDS) of the CuAAC reaction (Scheme 1). ${ }^{[9]}$ Chemoselective discrimination of alkynes is therefore possible by exploiting differences in their respective rates of acetylide formation. Modification of the alkyne to incorporate groups that facilitate a more rapid insertion of $\mathrm{Cu}$ into the alkyne $\mathrm{C}-\mathrm{H}$ bond has been a strategy employed by Finn, Hsung, and others in order to leverage chemoselective control in systems containing two alkynes, ${ }^{[10]}$ with mechanistic investigations focusing on this first key mechanistic event of the catalytic cycle..$^{[7-9,11]}$

Here we analyze the mechanistic origins of rateindependent chemoselectivity in CuAAC reactions of an aryl ynamine class of alkyne. Kinetic and spectroscopic investigations support the transition of the RDS from acetylide formation to azide ligation/migratory insertion.

C. P. Seath, Dr G. A. Burley, Dr A. J. B. Watson

Department of Pure and Applied Chemistry

University of Strathclyde

Glasgow, G1 1XL (UK)

E-mail: glenn.burley@strath.ac.uk; allan.watson.100@strath.ac.uk

Supporting information for this article is given via a link at the end of the document.

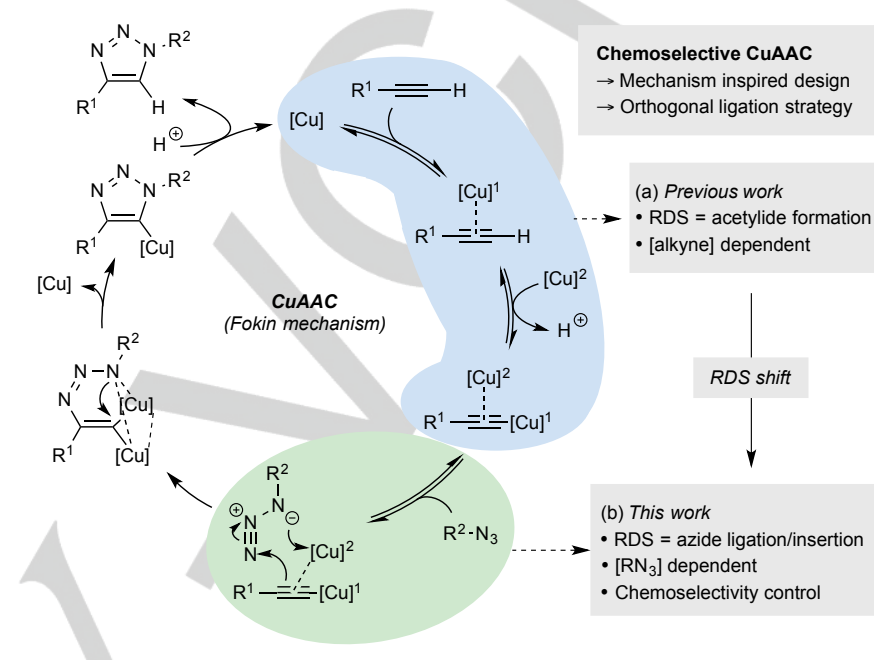

Scheme 1. Fokin's mechanism of the CuAAC reaction. ${ }^{[10]}$ (a) Chemoselectivity via acetylide formation RDS. (b) Chemoselectivity via azide ligation/insertion RDS.

Recently we have shown that aromatic ynamines are highly reactive alkyne substrates, which allow chemoselective CuAAC reactions in the presence of aliphatic alkynes irrespective of the nature of the azide used in the reaction. ${ }^{[12]}$ To probe and compare the reactivity of different classes of alkyne more broadly, we performed a series of competition experiments where equistoichiometric quantities of two terminal alkynes compete for one equivalent of a common azide component (benzyl azide, $\mathrm{BnN}_{3}$ ) using established reaction conditions (Scheme 2, see Electronic Supporting Information (ESI) for all triazole products)..$^{[4,8,12]}$
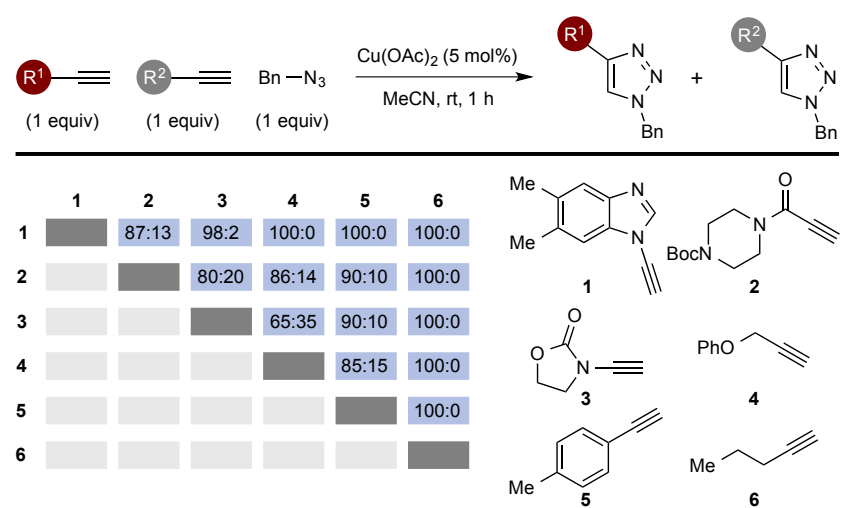

Scheme 2. Competition CuAAC reactions of systems containing two alkynes. Ratios are products arising from vertical number:horizontal number. Determined by ${ }^{1} \mathrm{H}$ NMR. See ESI. 
The alkyne selection was based on representative members of six specific classes - aromatic ynamine (1), tertiary propiolamide (2), ynamide (3), propargyl alkyne (4), aryl alkyne (5), and alkyl alkyne (6). Previous work by Finn has shown that 2 is a highly reactive substrate under conventional CuAAC conditions, outcompeting 4-6 in competition experiments. ${ }^{[10 a]}$ In addition, Hsung has shown that $3>5>6 .{ }^{[10 b, c]}$ Lastly, we have shown that $1>6 .{ }^{[12]}$ To assist in the selection of alkyne partners for chemoselective CuAAC applications, we sought to generate a reactivity scale ${ }^{[13]}$ that may inform the selection of alkyne partners for chemoselective click applications in multifunctional systems. $^{[3,10 a]}$

The data in Scheme 2 revealed the reactivity trend 1 $>2>3>4>5>6$. Ynamine 1 was the most reactive alkyne substrate, outcompeting all five other classes. Exclusive formation of the ynamine triazole product was observed over 3-6 and favored over 2 by approx. 8:1. Based on these initial observations, we sought to establish the origins of the rate acceleration of this chemotype in CuAAC reactions.
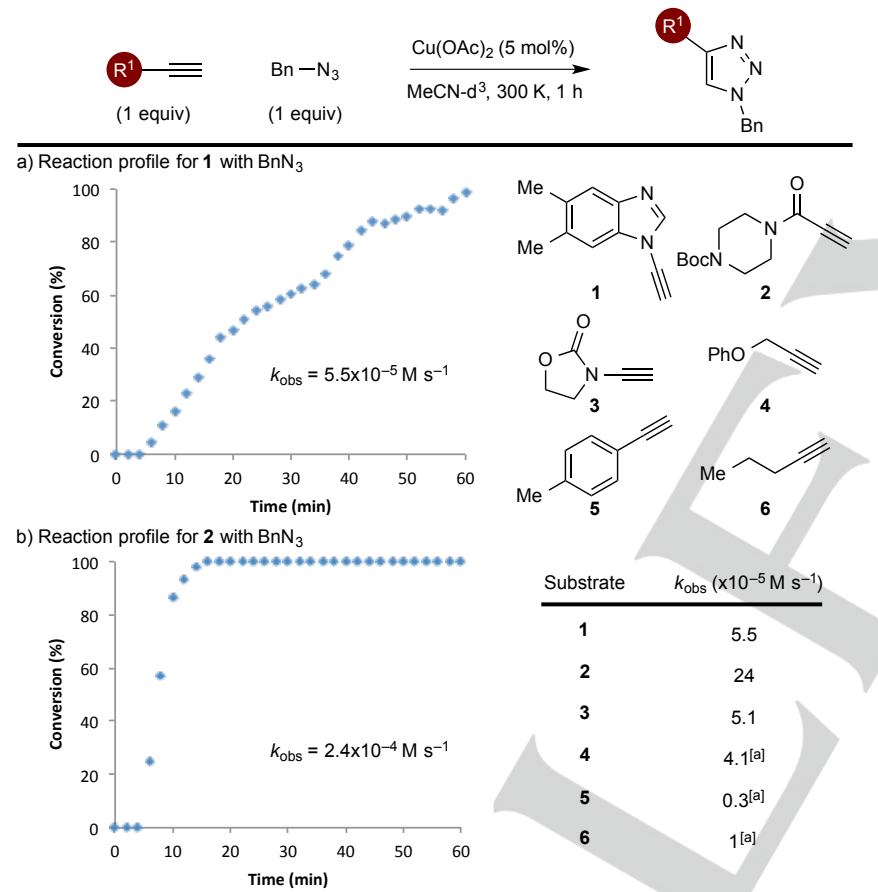

c) Reaction profile for competition reaction of $\mathbf{1 / 2}$ with $\mathrm{BnN}_{3}$

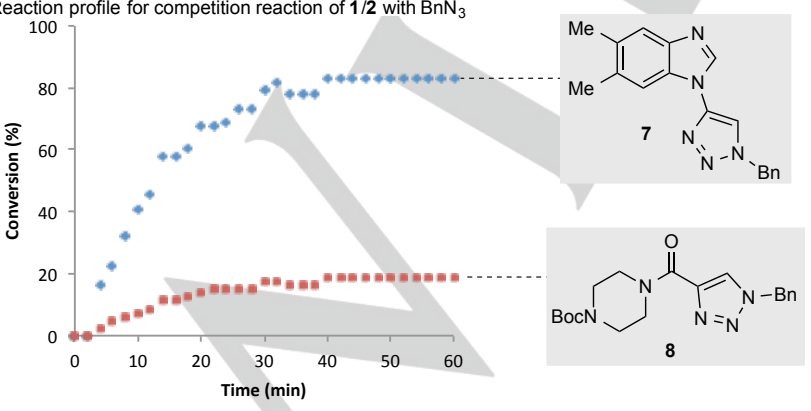

Figure 1. Reaction profiles for alkynes 1 (a) and 2 (b). Reaction profile for competition reaction of $\mathbf{1}$ vs. 2 and overall rate data for alkynes 1-6. Determined by ${ }^{1} \mathrm{H}$ NMR, see ESI. [a] Using NaAsc (10 mol\%).
Reaction Kinetics. Kinetic measurements by ${ }^{1} \mathrm{H}$ NMR allowed the establishment of rate data for each of the six classes of alkyne. Charts for alkynes $\mathbf{1}$ and $\mathbf{2}$ are provided in Figure 1; charts for 3-6 are provided in the ESI.

Based on the extracted $k_{\text {obs }}$, alkyne $2\left(2.4 \times 10^{-4} \mathrm{M} \mathrm{s}^{-1}\right)$ was fastest followed by ynamine $1\left(5.5 \times 10^{-5} \mathrm{M} \mathrm{s}^{-1}\right)$, which was marginally faster than alkyne $3\left(5.1 \times 10^{-5} \mathrm{M} \mathrm{s}^{-1}\right)$. The relative order of reactivity was in agreement with literature observations, including the requirement for reductant additives, such as sodium ascorbate ( $\mathrm{NaAsc}$ ), to promote the reactions of $\mathbf{4}$ as well as the less reactive aryl (5) and alkyl (6) alkynes. ${ }^{[14]}$

The kinetic data for 3-6 displayed a significant initiation time (3, 16 min; 4-6, >1 h), which, based on previous studies, we attribute to reduction of $\mathrm{Cu}(\mathrm{II})$ to a catalytically reactive $\mathrm{Cu}(\mathrm{I})$ species likely through oxidative homocoupling (Glaser coupling) of the alkyne. ${ }^{[8 a]}$ This initiation time could partly assist in explaining the origin of selectivity between 1 and 3 , where the reaction rates are almost identical. However, if the initiation time is a function of $\mathrm{Cu}(\mathrm{II})$ reduction, 1 clearly generates $\mathrm{Cu}(\mathrm{I})$ more rapidly (initiation time $=\sim 5 \mathrm{~min}$ ), and this would then accelerate both CuAAC reactions in the competition experiment, which was not observed. As such, the chemoselectivity in the competitive reaction containing $\mathbf{1}$ and $\mathbf{3}$ must have a different origin. Similarly, $\mathbf{1}$ has a slower rate than $\mathbf{2}$ but is the favored alkyne in the competition experiments, again, indicating a different origin of the observed chemoselectivity profile.

Deuterium kinetic isotope effect (KIE) experiments of the alkyne $\mathrm{C}-\mathrm{H}$ were informative. Zhu et al. reported a primary KIE of 2.3 when using an aryl alkyne (such as 5) and a marked increase in the initiation time associated with oxidative homocoupling. ${ }^{[8]}$ In agreement with these data, we observed primary KIEs (e.g., KIE for $2=2.66$ ) and a significant increase in initiation time (see ESI). In contrast a KIE of only 1.17 was observed for 1 (Figure 2a), indicating that Cu-acetylide formation was not rate limiting.

Further experiments revealed that the reaction rate of 1 was largely independent of [alkyne] (Figure 2b) but was heavily influenced by variation of $\left[\mathrm{BnN}_{3}\right]$ (Figure 2c). A zero-order dependency on [alkyne], and approx. second order dependency on $\left[\mathrm{RN}_{3}\right]$ were extracted (see ESI). ${ }^{[15]}$ This was a remarkable contrast to the data presented for more conventional alkynes, which display first order kinetics with respect to [alkyne] and a slight negative dependency in azide. ${ }^{[7]}$ Taken together, all of these data are consistent with a shift in the RDS of the CuAAC reaction using 1 as the alkyne substrate from acetylide formation to the azide ligation/migratory insertion event. These data assist in the explanation of the discrepancy between the observations that 1 outcompetes the other alkyne classes in the competition experiments in Scheme 2, despite displaying a rate that is slower than $\mathbf{2}$ and similar to $\mathbf{3}$ and $\mathbf{4}$.

Upon further analysis of the spectral data, the rate of $\mathrm{Cu}$ acetylide formation could be delineated from the primary rate data (Figure 2d). To further confirm our hypothesis, the rate of acetylide formation was twice as fast as the reaction as a whole. Accordingly, these data suggest that chemoselectivity is attained through a very rapid $\mathrm{Cu}$ insertion step, which is followed by a comparatively slow azide ligation/insertion step.

To better understand the origin of these observations, a series of control experiments were performed to understand the 
influence of the benzimidazole in the reaction. We postulated that an interaction between copper and the benzimidazole through N3 lowers the acetylinic $\mathrm{p} K_{a}$, resulting in rapid $\mathrm{Cu}$ acetylide formation. Indeed, synthesis and kinetic evaluation of the corresponding indole ynamine 9 revealed that the imidazole N3 is essential for chemoselectivity (Scheme 3 ).
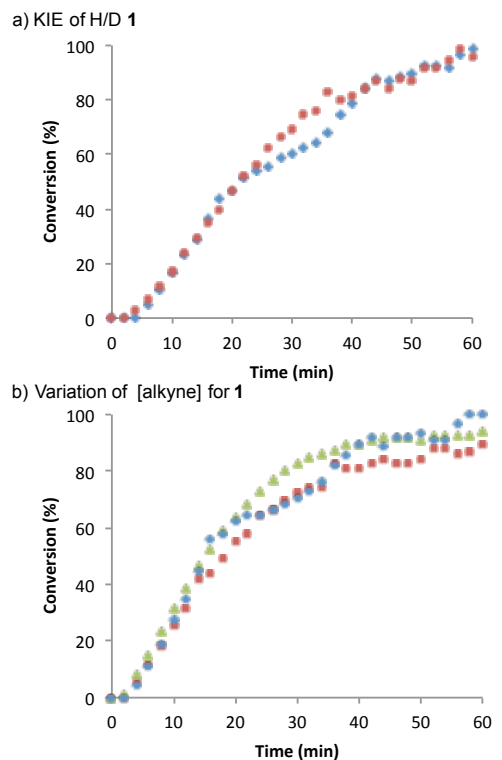

c) Variation of $\left[\mathrm{BnN}_{3}\right]$ for 1

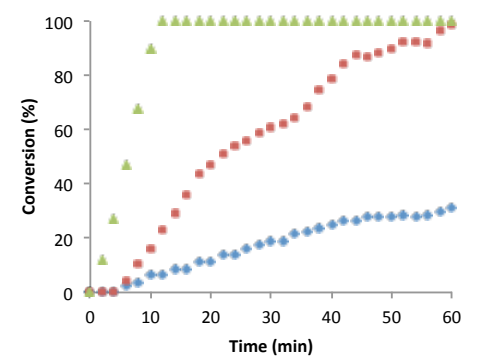

d) Acetylide formation vs. product formation using 1

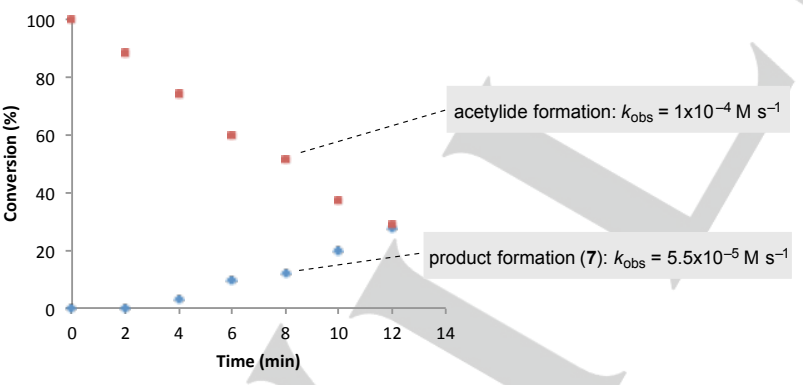

Figure 2. Kinetic isotope effect (a), the effect of [alkyne] variation (b), $\left[\mathrm{BnN}_{3}\right]$ variation (c), and acetylide formation vs. product formation for $\mathbf{1}$ (d).

In contrast to the $\sim 8: 1$ selectivity displayed by 1 in the same competition experiment, chemoselectivity was almost negligible in the reaction of $\mathbf{9}$ vs. $\mathbf{2}$, implying a pivotal role of N3 of 1.

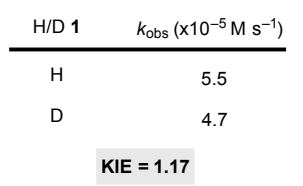

\begin{tabular}{cc}
1 & $k_{\mathrm{obs}}\left(\times 10^{-5} \mathrm{M} \mathrm{s}^{-1}\right)$ \\
\hline 1 equiv & 5.5 \\
1.5 equiv & 5.4 \\
2 equiv & 6.1
\end{tabular}

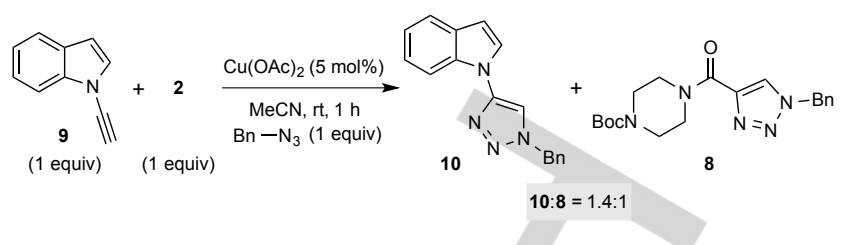

Scheme 3. Competition CuAAC reaction between 9 and 2. Determined by NMR. See ESI.

NMR analysis was used to probe the role of the benzimidazole N3 (Scheme 4). Treatment of 1 with $\mathrm{Cu}(\mathrm{I})$ or $\mathrm{Cu}(\mathrm{II})$ results in acetylide formation, which hindered interrogation of any $\mathrm{N}-\mathrm{Cu}$ interaction. However, addition of TIPS-protected ynamine 11 to $\mathrm{Cu}(\mathrm{OAc})_{2}$ resulted in the immediate formation of a new complex (12, Scheme 4a). No change was observed on treatment of 11 with $\mathrm{CuOAc}$, suggesting a $\mathrm{Cu}(\mathrm{II})$-specific interaction. Similarly, no change was observed upon treatment of the equivalent TIPS-protected 9 (13) with $\mathrm{Cu}(\mathrm{OAc})_{2}$ or $\mathrm{CuOAc}$ (Scheme 4a). The experiments suggest coordination of $\mathrm{Cu}(\mathrm{II})$ to N3 of 1.

a) Treatment of TIPS-derivatives with $\mathrm{Cu}(\mathrm{I})$ and $\mathrm{Cu}(\mathrm{II})$ and $\mathrm{NMR}$ analysis
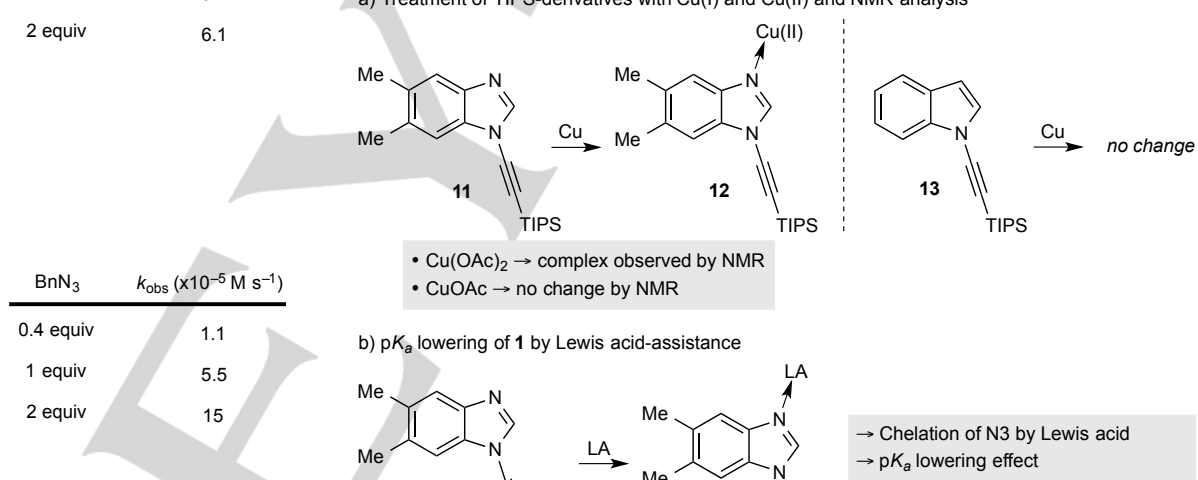

- $\mathrm{Cu}(\mathrm{OAc})_{2} \rightarrow$ complex observed by NMR - $\mathrm{CuOAc} \rightarrow$ no change by NMR

b) $p K_{a}$ lowering of 1 by Lewis acid-assistance

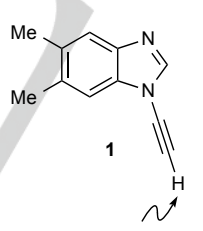

$\mathrm{p} K_{a}=27.9(\mathrm{MeCN})$

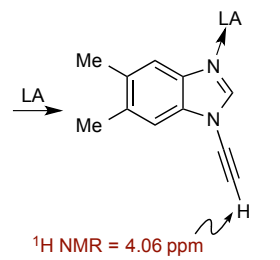

$\rightarrow$ Chelation of N3 by Lewis acid

$\rightarrow \mathrm{pK} K_{a}$ lowering effect

$\rightarrow$ Increased rate of acetylide formation

c) Rationale for comparatively slow azide ligation/insertion<smiles>C#Cn1cnc2cc(C)c(C)cc21</smiles>

$\rightarrow$ Electron-rich alkyne $\rightarrow$ Less electrophilic $\mathrm{Cu}$ $\rightarrow$ Slower azide ligation

Scheme 4. (a) Coordination of $\mathrm{Cu}(\mathrm{II})$ to $\mathrm{N} 3$ of 1 . (b) $\mathrm{p} K_{a}$ and ${ }^{1} \mathrm{H}$ NMR resonance of 1 and $1 \rightarrow L A$ complexes. (c) Rationale for slower azide ligation. $\mathrm{LA}=$ Lewis acid

The $\mathrm{p} K_{a}$ of the alkyne $\mathrm{C}-\mathrm{H}$ of 1 was determined to be 27.9 $(\mathrm{MeCN})$ by NMR titration with a ${ }^{1} \mathrm{H}$ NMR resonance of the alkyne $\mathrm{C}-\mathrm{H}$ at $3.67 \mathrm{ppm}$ (Scheme $4 \mathrm{~b}$ ). Treatment of 1 with Lewis acids that do not undergo $\mathrm{C}-\mathrm{H}$ insertion $\left(\mathrm{AlCl}_{3}, \mathrm{Sc}(\mathrm{OTf})_{3}\right)$ confirmed a substantial increase in the alkyne $\mathrm{C}-\mathrm{H}$ acidity, as demonstrated by a significant downfield shift. ${ }^{[16]}$ Cu-based Lewis acids could not be used for this purpose due to rapid acetylide formation. While the CuAAC process is catalyzed by $\mathrm{Cu}(\mathrm{I})$, UV analysis of 
reaction mixtures using 1 demonstrated that the reduction of $\mathrm{Cu}(\mathrm{OAc})_{2}$ to $\mathrm{Cu}(\mathrm{I})$ only proceeds to $\mathrm{ca}$. $50 \%$ : $\mathrm{Cu}(\mathrm{II})$ persists in the reaction mixture. HRMS of reaction mixtures supported these observations - a Cu(II)(1) $)_{2}$ complex was detected while no interaction was observed with $\mathrm{Cu}(\mathrm{II})$ and 9 (see ESI).

We hypothesize that the origin of the observed slower azide ligation event is due to the inherent electronics of 1 . Specifically, the alkyne is comparatively electron-rich due to the resonance contribution of the azole. This will, in turn, render $\mathrm{Cu}$ less electrophilic and slow down ligation/insertion of the electron-rich azide (Scheme 4c). The comparatively electron-rich nature of the alkyne of 1 is readily observed by ${ }^{13} \mathrm{C}$ NMR.

Collectively, we propose that the origin of chemoselectivity of 1 vs. other alkyne classes arises from $\mathrm{Cu}$ (II) coordination to the benzimidazole N3 resulting in an increase in alkyne $\mathrm{C}-\mathrm{H}$ acidity facilitating a rapid $\mathrm{Cu}$ acetylide formation (i.e., $k_{3}>k_{1}$; Scheme 5). The subsequent azide ligation/insertion event is then comparatively slower based on the electronics of the alkyne (i.e., $k_{4}<k_{3}$ ) and, as such, the RDS transitions to this event. Based on these data, the chemoselectivity-determining event is acetylide formation with RDS dependent on alkyne class and subtype.

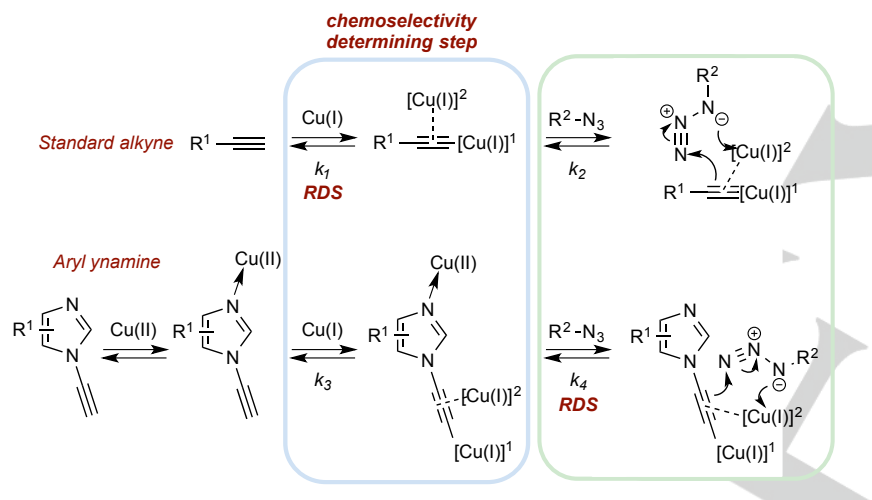

Scheme 5. Comparison of the chemoselectivity-determining and ratedetermining events for standard alkynes and aryl ynamines.

In conclusion, we have demonstrated that the RDS of the CuAAC reaction is non-constant and can be shifted away from the generally observed acetylide formation RDS. A benzimidazole class of aromatic ynamine undergoes chemoselective CuAAC reaction over a range of alkynes even in the presence of alkyne substrates that react, in isolation, at a faster overall rate (e.g., 2). Kinetic investigation shows that the RDS of the reaction has shifted from Cu-acetylide formation to azide ligation due to a rapid Lewis acid-assisted acetylide formation step. To the best of our knowledge this is the only report of chemoselectivity despite a lower overall rate. Up to this point, interrogation of this key mechanistic event has been limited, due to its rapidity with respect to acetylide formation. We anticipate that the unusual reactivity presented here will enable more detailed studies into the azide ligation/insertion step of this cornerstone reaction.

\section{Acknowledgements}

We thank the Carnegie Trust for a PhD Scholarship (CPS), GAB thanks the Alexander von Humboldt Foundation (Visiting Research Fellowship, LMU Munich). We thank Marine Hatit for the preparation of compound 1, Liam McLean for useful discussions, Craig Irving for assistance with NMR analyses, Julien Vantourout for assistance with mass spectroscopy, and the EPSRC UK National Mass Spectrometry Facility at Swansea University for analyses. We thank a Reviewer for an insightful point relating to azide dependency.

Keywords: chemoselectivity $\cdot$ click $\cdot$ CuAAC $\bullet$ kinetics $•$ ynamine

[1] For seminal reports, see: a) H. C. Kolb, M. G. Finn, K. B. Sharpless, Angew. Chem. Int. Ed. 2001, 40, 2004-2021; Angew. Chem. 2001, 113, 2056-2075; b) C. W. Tornøe, C. Christensen, M. Meldal, J. Org. Chem. 2002, 67, 3057-3064.

[2] a) J. E. Hein, V. V. Fokin, Chem. Soc. Rev. 2010, 39, 1302-1315; b) M. Meldal, C. W. Tornøe, Chem. Rev. 2008, 108, 2952-3015; c) J. E. Moses, A. D. Moorhouse, Chem. Soc. Rev. 2007, 36, 1249-1262.

[3] P. M. E. Gramlich, S. Warncke, J. Gierlich, T. Carell, Angew. Chem. Int. Ed. 2008, 47, 3442-3444; Angew. Chem. 2008, 120, 3491-3493.

[4] Z. Yuan, G. C. Kuang, R. J. Clark, L. Zhu, Org. Lett. 2012, 14, 2590-2593.

[5] V. Aucagne, D. A. Leigh, Org. Lett. 2006, 8, 4505-4507.

[6] For seminal reports see: a) J. E. Hein, J. C. Tripp, L. B. Krasnova, K. B. Sharpless, V. V. Fokin, Angew. Chem. Int. Ed. 2009, 48, 8018-8021; Angew. Chem. 2009, 121, 8162-8165; b) D. N. Barsoum, N. Okashah, X. Zhang, L. Zhu, J. Org. Chem. 2015, 80, 9542-9551. For synthetic examples see: c) K. Yamamoto, T. Bruun, J. Y. Kim, L. Zhang, M. Lautens, Org. Lett. 2016, 18, 2644-2647; d) W. Wang, F. Wei, Y. Ma, C.-H. Tung, Z. Xu, Org. Lett. 2016, 18, 4158-4161.

[7] V. O. Rodionov, V. V. Fokin, M. G. Finn, Angew. Chem. Int. Ed. 2005, 44, 2210-2215; Angew. Chem. 2005, 117, 2250-2255.

[8] a) G. C. Kuang, P. M. Guha, W. S. Brotherton, J. T. Simmons, L. A. Stankee, B. T. Nguyen, R. J. Clark, L. Zhu, J. Am. Chem. Soc. 2011, 133, 13984-14001; b) X. Zhang, P. Liu, L. Zhu, Molecules 2016, 21, 1697.

[9] B. T. Worrell, J. A. Malik, V. V. Fokin, Science 2013, 340, 457-460.

[10] a) A. A. Kislukhin, V. P. Hong, K. E. Breitenkamp, M. G. Finn, Bioconjugate Chem. 2013, 24, 684-689; b) X. Zhang, H. Li, L. You, Y. Tang, R. P. Hsung, Adv. Synth. Catal. 2006, 348, 2437-2442; c) X. Zhang, R. P. Hsung, L. You, Org. Biomol. Chem. 2006, 4, 2679-2682.

[11] a) L. Jin, D. R. Tolentino, M. Melaimi, G. Bertrand, Sci. Adv. 2015, 1 , e1500304; b) J. Jin, E. A. Romero, M. Melaimi, G. Bertrand, G. J. Am. Chem. Soc. 2015, 137, 15696-15698.

[12] M. Z. C. Hatit, J. C. Sadler, L. A. McLean, B. C. Whitehurst, C. P. Seath, L. D. Humphreys, R. J. Young, A. J. B. Watson, G. A. Burley, Org. Lett. 2016, 18, 1694-1697.

[13] For examples of reactivity scales, see: H. Mayr, A. R. Ofial, Acc. Chem. Res. 2016, 49, 952-965.

[14] F. Himo, T. Lovell, R. Hilgraf, V. V. Rostovtsev, L. Noodleman, K. B. Sharpless, V. V. Fokin, J. Am. Chem. Soc. 2005, 127, 210-216.

[15] A Reviewer suggested that this second order dependency may be due to an azide-promoted decomplexation of the N3-bound $\mathrm{Cu}(\mathrm{II})$. See ESI for a schematic description.

[16] D. G.Lee, R. Cameron, Can. J. Chem. 1972, 50, 445-448. 
Entry for the Table of Contents (Please choose one layout)

\section{COMMUNICATION}

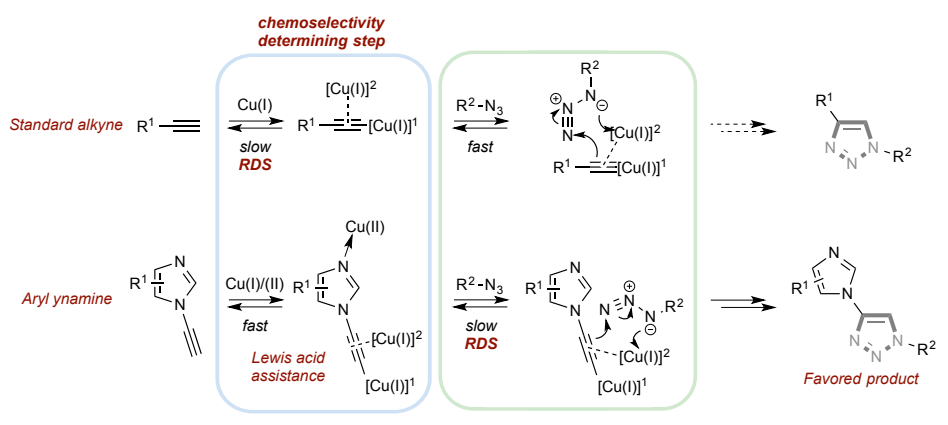

Ciaran P. Seath, Glenn A. Burley* and Allan J. B. Watson *

Page No. - Page No.

Determining the origin of rateindependent chemoselectivity in CuAAC reactions: An alkyne-specific shift in rate-determining step

The old switcheroo: We report a kinetic and spectroscopic analysis of alkyne-dependent chemoselectivity in the copper-catalyzed azide-alkyne click (CuAAC) reaction. Studies of six alkyne subtypes reveal that the rate-determining step (RDS) of an aromatic ynamine class is shifted from acetylide formation to the azide ligation/migratory insertion event allowing chemoselectivity independent of overall rate. 